\title{
Una perspectiva teórica de la dinamización de la carga de la prueba en el proceso penal colombiano*
}

\author{
A theoretical perspective of the dynamization of the burden of proof \\ in the colombian criminal process \\ Santiago Alejandro Montoya Vallejo ${ }^{1}$
}

Fecha correspondencia:

Recibido: 31 de agosto de 2020. Revisión: 26 de febrero de 2021. Aceptado: 9 de marzo de 2021.

Forma de citar:

Montoya, Santiago Alejandro. (2021) "Una perspectiva teórica de la dinamización de la carga de la prueba en el proceso penal colombiano." En: Revista CES Derecho. Vol. 12, No. 1, enero a junio de 2021, p. 58-78.

Open access

Términos de uso

Licencia creative commons

Etica de publicaciones

Revisión por pares

Gestión por Open Journal System

DOI: http://dx.doi.org/10.21615/

cesder.12.1.4

ISSN: 2145-7719

Sobre el artículo:

* Trabajo elaborado para la obtención del título de Especialista en Derecho Procesal, Universidad Libre, Seccional Cúcuta.

Sobre los autores:

1. Abogado, Universidad de Antioquia, Medellín. Especialista en Derecho Procesal, Universidad Libre, Seccional Cúcuta.

\section{Resumen}

La Constitución Política (Art. 29) y el Código de Procedimiento Penal (Art. 7 y 381) establecen como axiomas fundamentales la presunción de inocencia y el in dubio pro reo, otorgando en cabeza de la Fiscalía General de la Nación la carga de demostrar la responsabilidad penal proscribiéndose cualquier inversión y asumen como estándar probatorio el de más allá de toda duda razonable.

La Sala de Casación Penal de la Corte Suprema de Justicia ha teorizado sobre la aplicación de la carga dinámica de la prueba, situación que ha sido tildada como trasgresora de aquellos principios. Sin embargo, luego de un análisis teórico de esa jurisprudencia se concluyó que tal asunto en realidad no desdibuja tales cimentos ni cambia las reglas probatorias, sino que más bien se interesa por las defensas activas y una mayor aportación de elementos cognoscitivos, sin menoscabar las garantías fundamentales del procesado.

Palabras clave: Derecho procesal, derecho procesal penal, carga de la prueba, carga dinámica de la prueba, presunción de inocencia.

\section{Abstract}

The Political Constitution of Colombia (Art. 29) and the Criminal Procedure Code (Art. 7 and 381) establish as fundamental axioms the presumption of innocence and the in dubio pro reo, giving the Office of the Attorney General the responsibility of proving criminal liability, while proscribing any reversal and assuming the standard of proof beyond all reasonable doubt. The Criminal Cassation Chamber of the Supreme Court of Justice has theorized about the application of the reverse burden of proof, a situation that has been mentioned as transgressive of the abovementioned principles. However, after a theoretical analysis of that jurisprudence, it was concluded that it does not actually blur such principles or reverses evidentiary rules, but it rather concerns the active defenses and a greater contribution of cognitive elements, without undermining the fundamental rights of the accused. 
Keywords: Procedural law, criminal procedural law, burden of proof, reverse burden of proof, presumption of innocence.

\section{Introducción}

En atención a la presunción de inocencia, axioma orientador del derecho penal colombiano, paladino deviene que la carga de la prueba le corresponde a la Fiscalía General de la Nación, razón por la cual, se encuentra proscrito de nuestro ordenamiento jurídico cualquier inversión de la misma, conforme con el artículo $7^{\circ}$ del Código de Procedimiento Penal. Apotegma que informa todo el proceso, de donde se sigue que ante la inexistencia de soporte probatorio del hecho punible o de la responsabilidad del indiciado que corresponde aportarlo al ente persecutor, el juzgador debe absolver. Dicho de otro modo, de acuerdo con el artículo 381 ibídem para lograr la condena su deber es probar los elementos constitutivos del enunciado acusador con el estándar probatorio de más allá de toda duda razonable, so pena de desestimar la pretensión penal.

En el derecho actual, la máxima en comento, se insiste, es ampliamente reconocida como un principio capital elevado a categoría de derecho fundamental. En términos generales, consistente en que en todo momento y hasta que una sentencia ejecutoriada demuestre lo contrario, el juez debe considerar al indiciado como inocente. No obstante, conforme con Nieva Fenoll (2013), se establece como una regla que funciona más allá de la carga de demostración puesto que tendiéndose la ausencia de acreditación del enunciado acusador lo que deviene necesariamente es la inocencia. Así, esta presunción, según el profesor español, es más una regla de valoración de la prueba y no de la distribución de carga de acreditación de los hechos. Por lo tanto, no impone autorresponsabilidades a las partes para establecer sus estrategias litigiosas ni crea una regla de juicio para que el fallador establezca en contra de quien juzga la carencia de la actividad demostradora de sus dichos, sino que, es una herramienta para interpretar el juicio de hecho, es decir, la probanza del tema de prueba.

A pesar de la proscripción de que trata nuestro ordenamiento jurídico sobre la inversión de asunto en análisis, la Corte Suprema de Justicia a través de varios pronunciamientos ha expuesto la procedencia excepcional de la dinamización de esta institución. Postura que ha sido criticada por algunos académicos nacionales (Caro Espitia, 2013), con el argumento de que, bajo el principio de marras, que es trasversal a todo el proceso penal, el imputado siempre se reputa inocente y nunca se le puede abrogar el deber de probar su absolución. Inclusive, se ha tildado dicho intercambio de regla probatoria como contrario a la constitución (Páez Jaimes, 2018).

En varias oportunidades esa Alta Corporación manifestó que la carga de la prueba implica que quien alega un hecho con interés de parte, debe acreditarlo, de donde se podrían derivar consecuencias desfavorables ante el despliegue probatorio del adversario cuando se echa de menos la demostración de la circunstancia fáctica específica, que aun pudiendo ser aportada por quien resulta beneficiado no incorpora el respectivo medio de convicción.

Ese Tribunal de Casación ha estimado que la carga de la prueba en materia penal como desarrollo del principio de presunción de inocencia no es absoluta, so pena de avaluar una actitud pasiva de la defensa, toda vez que pueden presentarse situaciones de difícil acreditación para la parte acusadora, pero su contraparte defensiva con facilidad incorporaría el medio de convicción necesario para lo propio, por lo cual resulta plausible dicha dinamización, con el fin de restablecer el equilibrio en aras de que la 
demostración del aspecto debatido sea llevado a juico por la parte que tiene acceso al elemento de conocimiento, siempre y cuando éste último resulte beneficiado con dicha aportación. Lo anterior también se fundamenta en la ausencia de aplicación del principio de investigación integral, por lo que la actividad persecutora se agota con la acreditación de los elementos que cimientan la acusación y de la responsabilidad penal del indiciado, en consecuencia, la defensa adquiere el compromiso de probar circunstancias que desvirtúen el fundamento fáctico acusador o de lo contrario se expone a una posible condena (Corte Suprema de Justicia, 2017).

Asimismo, dicha Corporación ha manifestado que, una vez el ente investigador cumpla con la carga de la prueba para determinar la existencia del delito y la participación del implicado, si la defensa pretende controvertir la capacidad suasoria de estos elementos, debe aportar medios de juicio tendientes a refutarlos. De donde se deduce la aplicación del concepto pergeñado, que es de uso restrictivo, no para que la defensa acredite lo que es deber del ente acusador sino para desvirtuar lo probado por este. Asunto que se encuentra justificado en la introducción de racionales anejado con las pretensiones de las partes y las herramientas necesarias para demostrarlas (Corte Suprema de Justicia, 2018).

Pues bien, con esta investigación se pretende analizar el criterio de la Corte Suprema de Justicia y de la doctrina colombiana, bajo las conceptos teóricos procesales que fundamentan la presunción de inocencia y los relacionados con la misma, como la duda a favor del reo, el estándar de prueba más allá de toda duda, la carga de prueba y su dinamización, con miras a indagar si dicha posición en efecto comporta una inversión, lo que de contera implicaría imponerle a la defensa necesariamente el deber de demostrar su inocencia con el estándar probatorio más allá de toda duda razonable, lo cual, a la postre y sin duda alguna genera una gravísima mengua al aforismo referenciado. 0 si por el contrario tal postura, no es precisamente una inversión del tema de prueba o una acreditación de la inocencia del acusado, sino que resulta como una regla práctica, que si bien se origina con problemas en su formulación jurisprudencial, podría sustentarse desde la concepción de la carga de acreditar los hechos que le interesan a la parte resistente de la pretensión punitiva, siendo que con un estándar probatorio de probabilidad contribuya a la incorporación de circunstancias fácticas para ser valoradas por el juzgador, en desarrollo de una defensa activa.

La investigación se realizó a partir de un enfoque dogmático del derecho, en tanto pretende analizar las normas e instituciones jurídicas en sí mismas, su interpretación, postulados teóricos y desarrollos jurisprudenciales. Se utilizó una metodología de corte cualitativo, que permitió abordar, por un lado, los conceptos y referentes teóricos relacionados con el objeto de estudio y, por el otro, la jurisprudencia y la doctrina locales que lo explican y aplican. Esto se logró mediante la técnica de investigación de revisión de fuentes documentales, tales como el ordenamiento jurídico que regula el asunto, la jurisprudencia que lo ha intentado exponer y algunos autores nacionales y extranjeros que han examinado no solo el tema sino otros anejados con el mismo que permiten una mayor y mejor compresión teórica para llegar a las conclusiones acá propuestas. A su vez, el proceso de recopilación de la información fue realizado mediante el instrumento de fichaje de fuentes bibliográficas para ser contrastadas y analizadas a la luz de esos conceptos y categorías. Todo esto permitió establecer una perspectiva teórica de la dinamización de la carga de la prueba en el proceso 
penal a través de un estudio sintético doctrinal sobre esa institución jurídica y los conceptos que ayudan a entenderla, aplicándolo a la forma cómo la doctrina y jurisprudencia nacional la han desarrollado.

\section{Conceptos teóricos relacionados con la dinamización de la carga de la prueba en el actual proceso penal colombiano - Ley 906 de 2004 -}

\subsection{La presunción de inocencia e in dubio pro reo}

La presunción de inocencia es ampliamente reconocida como un principio informador del proceso penal con categoría de derecho fundamental, consistente en que en todo momento y hasta que una sentencia ejecutoriada demuestre lo contrario, el juez debe considerar al indiciado como inocente. No obstante, dicho axioma capital, conforme con Nieva Fenoll (2013), se presenta más allá de una regla de la carga de la prueba. Según este, tal axioma no funciona propiamente como un sucedáneo de prueba que tenga como fin evitar el non liquet, por lo tanto, no va dirigido a que las sentencias absolutorias se motiven en la falta de prueba, sino que su función radica en que cuando el fallador valora la ausencia de acreditación del enunciado acusador resulta abocado a declarar la inocencia.

Lo anterior por cuanto esta presunción es más una regla de valoración de la prueba y no de la distribución de carga de acreditación de los hechos, por lo tanto, no impone autorresponsabilidades a las partes para establecer sus estrategias litigiosas ni crea una regla de juicio para que la autoridad judicial establezca en contra de quien juzga la carencia de la actividad demostradora de sus dichos. En cambio, es una herramienta para interpretar el juicio de hecho, es decir, la acreditación del tema de prueba. En el mismo sentido, expresa Mosquera Mosquera (2015) que la presunción de inocencia entendida como regla del juicio de hecho con implicaciones probatorias, indica que es requisito sine qua non para que el procesado resulte condenado que el acusador pruebe todos los elementos del tipo penal, de lo contrario será absuelto.

El apotegma en comento conserva su justificación cuando se acepta que condenar a un ciudadano inocente comporta mayor gravedad que absolver a uno culpable, razón por la cual se impone un deber al juzgador de interpretar a favor del enjuiciado las insuficiencias y ambigüedades probatorias (Nieva Fenoll, 2013). Se itera, la presunción de inocencia no se explica solamente como un sucedáneo de prueba que se aplica solo cuando se echa de menos la acreditación de los enunciados fácticos propuestos por las partes, sino que además resulta útil cuando existe actividad probatoria, empero comporta insuficiente. Por consiguiente, también en este evento se debe preferir la no culpabilidad del imputado, no por ausencia de prueba de su culpabilidad sino por cuanto no se logró desvirtuar la inocencia.

De esta manera, la presunción de inocencia y el estándar probatorio "más allá de toda duda razonable" tienen como finalidad principal volver al juez más imparcial, alejándolo del prejuicio social de que implicado es culpable. En consecuencia, ante la ausencia de datos objetivos que permitan inferir la responsabilidad penal no queda otro camino que absolver, porque permitir condenas sin pruebas resultaría insoportable (Nieva Fenoll, 2016). 
La presunción de inocencia contiene entonces tres garantías básicas i) imparcialidad judicial, en tanto que el juzgador concibe al indicado como inocente a pesar de la existencia de un enunciado fáctico que pretende acusarlo; ii) ausencia de condena sin pruebas ya que para proferir sentencia condenatoria es requisito esencial la acreditación de cada uno de los elementos del tipo penal imputado; y iii) el derecho a no ser violentado como consecuencia de una indagación, lo que significa que debe ser tratado como inocente durante todas las etapas del proceso penal desde la investigación hasta la sentencia ejecutoriada y además comprende la no vulneración de los derechos del investigado, salvo que medie autorización judicial.

Dicho sea de paso que no existe total consenso frente a la existencia de distinción entre el in dubio pro reo y la presunción de inocencia por cuanto mientras que Nieva Fenoll (2016) expresa que son exactamente el mismo principio y carece de todo sentido distinguirlos, pues su única diferencia es que el primero es una antigua formulación del segundo; Parra Quijano (2011) advera que la presunción de inocencia informa todo el proceso penal y significa que ante la falta de prueba del hecho punible o de la responsabilidad del indiciado se debe absolver y el in dubio pro reo se presenta cuando existe actividad probatoria, empero si se presenta duda, resulta perentoria la absolución.

Distinción que ha sido también tratada por la jurisprudencia patria al explicar que bajo el primer concepto a quien se acusa de haber cometido un crimen se le debe tratar durante todo el proceso como inocente, es decir, rige en todas las etapas y el segundo se aplica exclusivamente en la valoración probatoria en tanto si existe una duda razonable sobre la concurrencia de los elementos del tipo penal debe resolverse en favor del procesado (Corte Suprema de Justicia, 2020). Separación que acá se acoge entendiendo que el segundo concepto es una manifestación o "realización plena" (2018) del primero, pero específicamente en el juicio de hecho. En todo caso ambas figuras hacen parte del principio de favorabilidad y son garantías torales del proceso penal que edifican la idea de que para condenar se debe tener certeza limitando el poder punitivo del Estado.

También resulta necesario advertir que no todos los autores estudiados entienden la presunción de inocencia como una verdadera presunción, ya que, verbigracia, el autor extranjero en comento (2013) aduce que la misma carece de hecho base, indicio o antecedente. Sin embargo, el maestro colombiano (2011) la comprende como una verdadera presunción basada en la regla de la experiencia que da cuenta que la mayoría de las personas se abstienen de cometer delitos por lo cual se presume la inocencia en vez de sospechar la culpabilidad del ciudadano investigado. Esta posición la comparte Charry Rivas (2015) al entenderla como una de carácter ideológico, siendo lo normal que los hombres no cometan crímenes. Con todo, este escrito también se mantendrá al margen de la discusión por desbordar el objetivo general.

\subsection{Estándar de prueba más allá de toda duda razonable}

Cierto es que la duda es un elemento esencial en la generalidad de los asuntos sometidos al conocimiento de la jurisdicción (Nieva Fenoll, 2013) pues de lo contrario, si al inicio del proceso existiese absoluta claridad en el derecho sería innecesario activar la administración de justicia, porque precisamente en un litigio se debaten derechos ante la falta de seguridad de los mismos. En el proceso penal en particular, aunque en algunas oportunidades la materialización de la conducta resulta diáfana, verbigracia el acaecimiento de una muerte o un detrimento patrimonial, se discuten en la práctica probatoria la responsabilidad del imputado o su grado de culpabilidad. 
Por consiguiente, como el proceso judicial tiene como fundamento la duda, dentro del juicio de hecho resulta imperativo para el juez resolver conforme con los datos y elementos de conocimiento incorporados. Esto es, decidir en primer lugar sobre la acreditación de las hipótesis planteadas por las partes y luego interpretar la norma sustancial aplicable. Y aunque en ese análisis interpretativo también pueden surgir discusiones, para el objetivo de este escrito, se destacará sólo la duda frente a los enunciados fácticos.

En atención al non liquiet, es obligación del juez solventar la duda sobre las circunstancias del caso fáctico debatido, es decir, tiene que resolver el litigio de fondo, con la prohibición de abstenerse o inhibirse por falta de claridad en los fundamentos fácticos o jurídicos. Por cuanto la función jurisdiccional tiene como finalidad la preservación de la paz social y la terminación de los conflictos, siendo que una prolongación innecesaria de los mismos puede acabar provocando una tensión pública que ponga en riesgo la estabilidad social, por esta razón al pronunciamiento judicial se le otorga los efectos de cosa juzgada (Nieva Fenoll, 2013).

Por consiguiente, en la actividad probatoria se requiere un parámetro para que el fallador entienda como acreditado las hipótesis planteadas por las partes en contienda. Así aparece la institución jurídica conocida como estándar de prueba que tiene como función indicar el grado de convencimiento sobre un hecho para declararlo probado. En el derecho penal aplica el conocido como "más allá de toda duda razonable" que se encuentra directamente relacionado con la presunción de inocencia en tanto estas dos figuras, al igual que el in dubio pro reo, fundamentan una misma idea, todo procesado debe ser considerado inocente antes de ser declarado culpable (Nieva Fenoll, 2016). A su turno, en el proceso civil conforme con la doctrina estadounidense, se impuso un método de sopesar las probabilidades teniéndose que valorar la prueba en su conjunto y al final se decide por la posibilidad que parezca más plausiblemente verdadera que falsa (Nieva Fenoll, 2013).

En suma, el estándar de prueba es una directriz que indica la forma de resolver el asunto litigioso cuando no se establezca en el juicio de hecho un determinado grado de solidez de la hipótesis acusatoria, con base en las pruebas incorporadas. Convirtiéndose en una forma de distribuir el error judicial existente, que puede suceder debido a que la sentencia no se fundamenta en juicios realizados a los hechos mismos de los cuales se podría predicar su falsedad o verdad, sino sobre valoraciones de los enunciados fácticos presentados por las partes en contienda. Por consiguiente, tal institución es un baremo que sirve para indicar cuando un enunciado fáctico es considerado falso o verdadero, pero no sirve para establecer el grado de apoyo del mismo, no recurre para encontrar la verdad, su función es distribuir el error, esto es, no reduce el yerro judicial, sino que lo desplaza a favor del procesado, sea culpable o inocente. (López Pinilla, 2016)

Se insiste, el estándar probatorio consiste en que sólo podrá condenarse cuando se haya alcanzado la "certeza" de la culpabilidad mientras que debe absolverse incluso cuando se presenten dudas razonables de que sea inocente al evaluarse las pruebas que presentase el ente investigador, buscando así proferir sentencias condenatorias únicamente cuando se establezca que el imputado es culpable con certidumbre o un grado de convicción muy alto. Sin embargo, la definición de razonable o no razonable, es un concepto indeterminado, por lo cual el juez en cada caso en particular determinará la existencia de la duda. Por lo que esta figura jurídica corresponde 
más bien a una decisión política y moral mediante la cual se entiende que la condena debe ser dictada únicamente cuando exista una certeza de culpabilidad, aun cuando no pueda ser analizada en grados estrictos de acreditación (Taruffo, 2005).

No obstante, en un intento de formulación del estándar en materia penal que es el que acá interesa, puede considerarse que una hipótesis se encuentra acreditada más allá de toda duda razonable cuando:

a) Tenga un alto nivel de contrastación de manera que explique los datos disponibles y ser capaz de predecir nuevos datos que hayan sido corroborados.

b) Deban ser refutadas todas las demás hipótesis plausibles que quepan construir con los mismos datos que sean compatibles con la inocencia. (Nieva Fenoll, 2016, pág. 12)

\subsection{Carga de la prueba y su dinamización}

Bajo el marco ideológico liberal surge como la regla que encamina a las partes a probar el supuesto de hecho de que trate la norma que pretende ser aplicada para que los efectos de la consecuencia jurídica resulten a su favor (Parra Quijano, 2011). No obstante, con el advenimiento de las ideas del Estado Social de Derecho y el principio de solidaridad, se generó una variación de dicha regla, aplicándose la dinamización de la misma, que consistente en que en los eventos en que se presente una dificultad probatoria, la parte que se encuentra con mayor facilidad de acreditar el suceso deberá incorporarlo a juicio.

Taruffo -citado por Charry Rivas (2015)- aduce que por regla general el litigio se resuelve conforme con lo acreditado como hipótesis fáctica de la parte, que se reputa a la postre como verdadera quedando la duda superada. Sin embargo, cuando esto no sucede porque no han sido probados todos o algunos hechos principales, por falta de apoyo o inexistencia, porque existen pruebas positivas o negativas, o porque las partes no las han presentado, el juez está obligado a decidir viéndose compelido a aplicar como criterio jurídico la carga de la prueba.

La que puede ser entendida en dos aspectos: i) como una regla de autorresponsabilidad de las partes frente al juicio de hecho fijando la necesidad de la aportación de medios de conocimiento para sustentar lo pretendido por cada parte, es decir, da cuenta del tema de prueba que debe ser acreditado con el fin de que se aplique la norma invocada a su favor; y ii) como un regla de juicio que indica la menara de fallar cuando no aparezcan probados determinados hechos, siendo un sucedáneo que resulta aplicable cuando la actividad probatoria fracasa, porque como el juez no puede inhibirse de un pronunciamiento de fondo, debe aplicar la regla en cita (Parra Quijano, 2011). En el mismo sentido lo define Devis Echandia -como lo cita Charry Rivas (2015)- advirtiendo que la carga de la prueba es una regla de juicio que señala la manera de resolver el debate fáctico cuando haga falta la acreditación de los sucesos alegados, actuando al tiempo como un sucedáneo de la prueba y como una regla de conducta para las partes en contienda, determinando indirectamente cuales hipótesis les conviene acreditar para que sean consideradas verdaderas. Pero en todo caso con la deficiencia de la prueba en materia penal resulta favorecido el acusado. 
Dicha institución determina quién debe probar, la manera en cómo se realiza la recolección de las pruebas y finalmente los elementos que tiene en cuenta el fallador en caso de presentarse incertidumbre probatoria (Ávila Roncancio, y otros, 2013). En materia penal, como regla de comportamiento de las partes indica que al ente acusador le corresponde demostrar todos los elementos del tipo penal, esto es, una conducta, típica, antijurídica y culpable, con sus agravantes, aspectos objetivos y subjetivos, y como regla de juicio indica que en caso de duda de las particularidades de la conducta delictiva, se resolverá a favor de la defensa.

Según Nieva Fenoll, la institución en comento es propia del derecho civil, cimentada en los principios dispositivo ${ }^{1}$ y de apropiación de parte ${ }^{2}$, por lo que si el litigante aporta la prueba que le es más disponible, puede ganar el caso, de lo contrario lo perderá (2013). En cambio, en el proceso penal el ente acusador al igual que el juez actúan bajo el principio de objetividad, razón por la cual el delegado persecutor no tiene la carga de demostrar, sino el deber de realizar actividades probatorias con el fin de que la verdad de los hechos resulte aclarada. Aunado a que el fiscal como servidor público actúa bajo el principio de legalidad, por lo que no se encuentra sujeto a cargas sino al cumplimiento de sus funciones y obligaciones (Nieva Fenoll, 2016).

Para el profesor Parra Quijano, como lo refiere Charry Rivera (2015), la carga de la prueba en materia penal no aplica, es decir, no existe el sucedáneo de la prueba ya que el descuido probatorio no lo sufre la Fiscalía General de la Nación porque no es un perjuicio procesal en contra del ente acusador, sino que la duda se resuelve a favor del reo. Razón por la cual en estos asuntos conviene destacar mejor la institución de la presunción de inocencia, teniéndose así al procesado, lo que no es óbice, a veces con calidad de exigencia, que la defensa contribuya con el esclarecimiento de la conducta enjuiciada.

Ahora bien, la carga dinámica de la prueba surge en las ocasiones en que existe una desigualdad procesal en la que una de las partes se encuentra con una mayor facilidad para acreditar un hecho (López Pinilla, 2016). A decir de Nieva Fenoll (2013), una vez fracasada la valoración probatoria el juez debe realizar un juicio eminentemente indiciario para establecer a que parte le resultaba más sencillo probar un hecho determinado, y así, bajo la máxima de la experiencia "si quien podría probar el hecho no ha aportado dicha prueba, ello sería porque esa prueba le podía perjudicar" (2013, pág. 46). En consecuencia, se juzga contra quien se abstuvo por rebeldía de aportar el elemento de conocimiento, dándole la razón a su parte contraria. Sin embargo, dicha dinamización es inaplicable al proceso penal por cuanto acudir al sucedáneo de prueba implica que las otras pruebas son insuficientes para demostrar la responsabilidad del implicado, teniéndose que absolver, de cara a la presunción de inocencia.

Con todo, también se ha dicho que bajo el sistema acusatorio y en atención a que el órgano persecutor no está vinculado por el principio de investigación integral ${ }^{3}$, resulta aplicable la carga dinámica de la prueba en el proceso penal. La que consiste en que cuando el ente investigador cumpla con la carga requerida para demostrar el acaecimiento de la conducta punible endilgada al acusado y su participación, si la defensa tiene la pretensión de debatir la prueba incorporada por la Fiscalía, debe adelantar una actividad además de argumentativa también demostrativa para obtener los medios de convicción que refuten la culpabilidad e incorporarlos a la práctica 1. Implica que en manos de los particulares está la decisión de acudir al proceso, iniciarlo y continuarlo en las distintas instancias, así como concretar el objeto del litigio.

2. Supone que son las partes, que no el juez, las que deben aportar los hechos y sus respectivos medios de prueba.

3. Por cuanto, la Fiscalía General de la Nación no tiene el deber de investigar lo favorable y desfavorable al implicado, sino que se enfoca en desvirtuar la presunción de inocencia, esto es, buscar los elementos de conocimiento que lleven al convencimiento del juez del acaecimiento de una conducta delictiva, no obstante, en el evento de que encuentra evidencia favorable al procesado las debe poner a disposición de la defensa. (Corte Constitucional, 2005) 
probatoria. Y si resultan insuficientes para desvirtuar los cargos no podría exigírsele al acusador el aporte de los elementos de conocimiento para ello, ni tampoco podría invocar la defensa la aplicación de in dubio pro reo (Urbano Martínez, 2012).

\section{El dinamismo de la carga de la prueba en el proceso penal colombiano, desde la jurisprudencia y la doctrina locales}

\subsection{Análisis jurisprudencial de la carga dinámica de la prueba y su aplicación en el sistema penal acusatorio}

De acuerdo con la Corte Suprema de Justicia (2016) la carga de la prueba comporta una necesidad de aportar un elemento de conocimiento demostrativo de una situación fáctica que favorece a una de las partes. Imponiéndosele dicha obligación, so pena de derivarse consecuencias negativas por su comportamiento procesal, en el evento en que se eche de menos la acreditación del suceso que la beneficia, siempre y cuando teniendo la facilidad para ser aportada la omite y su contraparte acredita su pretensión.

Mientras que la regla de la carga dinámica de la prueba, de creación jurisprudencial, la define la Corte Suprema de Justicia (2011) como la carga que tiene la defensa de demostrar determinados acontecimientos en situaciones particulares donde emerge una dificultad para la institución acusadora de probarlos cuando la parte acusada cuenta con la facilidad de incorporar el elemento de conocimiento, siempre que resulten beneficiados sus intereses. Lo anterior con el fin de restablecer el equilibro para que la acreditación de la circunstancia fáctica controvertida sea aportada por la parte que tenga la mejor forma de acceder a ella. Dicha dinamización la justifica la Corporación en que en materia penal el principio de presunción de inocencia y el derecho a la igualdad no son absolutos y no pueden avalar un comportamiento pasivo de la defensa. Aunado, dicho intercambio probatorio halla cimento en un sistema penal acusatorio, donde no rige el principio de investigación integral. Razón por la cual el procesado adquiere un compromiso en demostrar los elementos que se pretenden oponer al soporte fáctico de la acusación, so pena de resultar expuesto a una condena.

En otra oportunidad adujo la Corporación que cuando existan medios probatorios que sólo se hallan a la mano del procesado y si con su utilización se pretende acreditar situaciones que debaten las pruebas recaudadas en su contra, no es posible exigírsele a la Fiscalía General de la Nación que los conozca. Asunto que explica que la carga dinámica se aplica en estos eventos para desvirtuar lo probado por el ente estatal, que no para que el accionado acredite lo que compete al Estado. Situación que no pugna con el concepto clásico de la carga de la prueba en materia penal, ni tampoco afecta garantías fundamentales (2011, Corte Suprema de Justicia). Pues bien, en este pronunciamiento no se observa una idea que desplace la obligación de acreditar un hecho de la teoría de la acusación hacia la defensa, por el contrario, establece la posibilidad que tiene la defensa de incorporar elementos de conocimiento para controvertir la pretensión que resiste.

En sentencia de 2008, la Corte adveró que la carga dinámica de la prueba se relaciona con la exigencia procesal que le cabe a la parte que posee un elemento de convicción de que lo aporte al juicio para obtener las consecuencias jurídicas que busca. Y advirtió que dicho cambio debe ser excepcional, pues no se puede variar la obligación probatoria de los elementos constitutivos del tipo penal en cabeza de 
la Fiscalía General de la Nación. Aclarándose que luego de realizada dicha actividad acreditadora, si la defensa intenta debatir la capacidad suasoria de los mismos, es a esta quien le compete traer al litigio los medios de juicio suficientes que soporten su enunciado fáctico. En dicha oportunidad también se dijo que como la procesada era la única parte con posibilidad de incorporar medios de convicción encaminados a controvertir el material probatorio que cimentó la captura en flagrancia, se colige que incumplió con las mínimas exigencias.

En sentencia de febrero de 2017, la Corte analizó la sentencia de instancia que condenó por el delito de peculado a un alcalde que realizó gestiones con el fin de obtener mercancías para la población más vulnerable, siendo asignadas a la municipalidad, empero, después de firmar unas autorizaciones para la entrega del material a terceros no fueron ingresadas en su totalidad al almacén de la administración ni fueron repartidas entre la ciudadanía. El censor alegó que no se demostró la apropiación de las dotaciones desatendiéndose las explicaciones narradas y que como el ad quem aceptó el desconocimiento del paradero de los bienes se configura el peculado culposo al confiar en terceras personas. Finalmente se desestimó por insuficiencia argumentativa la demanda de casación, no obstante, se hizo alusión a la carga dinámica de la prueba al manifestarse que ante situaciones en que el ente estatal se encuentra con dificultad probatoria para acreditar determinado hecho y la defensa cuenta con el medio para lo propio, siempre que esté en línea con sus intereses, se hace necesario reestablecer el equilibrio para que sea aportada por la parte que tenga acceso a ello. También reiteró que la defensa adquiere el compromiso de demostrar el soporte fáctico que refuta la acusación, en virtud del sistema penal acusatorio donde no rige la investigación integral a cargo de la Fiscalía.

Pues bien, desde ya se advierte que en estricto sentido teórico procesal, lo definido por el Tribunal de Casación no deviene como carga de la prueba dinámica. Y si bien será sustentada en el siguiente acápite del escrito dicha posición, a continuación, se realizará un recuento de reciente jurisprudencia, donde, a pesar de que la defensa recurrente, los jueces de instancia o la misma Corte utilizan el concepto explicado. Asimismo, se intentará examinar que el intercambio probatorio no es dable jurídicamente.

En sentencia de la Corte Suprema de Justica (2017) se condenó a un Fiscal por archivar una indagación preliminar con base en una conciliación inexistente, obrando por fuera del marco de la ley conforme con sus conocimientos jurídicos, por cuanto dentro del expediente se evidenció la falta de celebración de la supuesta conciliación. Por lo tanto no le era posible archivar el proceso investigativo, echándose de menos la respectiva acta y sin explicaciones razonadas que hicieren inferir que presentándose tal omisión el acto de conciliación en efecto se llevó a cabo, puesto que el denunciante en el proceso desestimado llama la atención sobre su archivo.

En esta oportunidad se adujo que pretermitir el documento no fue explicado por la defensa, quien relató una versión que no estaba respaldada probatoriamente resultando inatendible, lo que implica tener como verdadera tal omisión. Dicho de otra manera, de haberse ejecutado la conciliación la defensa debió acreditarla, de cara al interés que tenía sobre el asunto y a la facilidad de demostrar la situación, por cuanto bajo la Ley 906 de 2004, quien afirma un supuesto fáctico tiene la carga de demostrarlo. Empero, ante la inactividad probatoria de la defensa, la hipótesis de la Fiscalía probada fehacientemente resultó próspera, pues, de cara a la falta de conciliación era inviable la realización del archivo. Lo anterior, ya que una vez valorada 
integralmente las pruebas practicadas, se coligió que la afirmación de la defensa no era cierta, por cuanto adolece de considerables inconsistencias que ratifican la inexistencia del acto conciliatorio.

De este evento se sustrae que, aunque en esa providencia se utilizó el concepto jurisprudencial en análisis, en verdad no se aplicó, toda vez que el sentenciador y la misma Corte analizaron en conjunto la prueba motivándose la condena en que el ente persecutor logró demostrar su hipótesis más allá de toda duda razonable. Y aunque hubo actividad probatoria y argumentativa del procesado, sus elucubraciones fueron desatendidas pues desde la sana crítica se consideraron ajenas a la realidad. En consecuencia, no se estaba imponiendo una carga de probar su inocencia o la no ocurrencia del prevaricato o la ejecución de la conciliación, sino que ante el intento de crear un enunciado fáctico defensivo debió acreditarlo con algún grado de plausibilidad, que no con el estándar probatorio exigido a la Fiscalía.

En providencia de abril 5 de 2017, (Corte Suprema de Justicia) se expuso que cuando la defensa está en desacuerdo con el contenido demostrativo de los medios de convicción utilizados por el ente persecutor los debe refutar mediante evidencias que soporten su teoría del caso, ya que en igualdad de armas el acusado tiene la facultad de recabar pruebas para ejercer la contradicción. Postura que se reafirmó en proveído del 26 de idéntico calendario al advertir que cuando el acusado está no comparten el contenido de uno o varios elementos de convicción aportados por la Fiscalía tendientes a acreditar su teoría del caso, debe controvertirlos. Con mayor razón cuando se trata de un sistema adversarial, por cuanto ambas tienen la facultad de obtener elementos cognitivos para sustentar sus afirmaciones y pretensiones.

De esta manera, en efecto no se trata de dinamización de carga de la prueba, esto es, la necesidad de probar un hecho que es deber de la Fiscalía acreditar, pero que ante la facilidad de la defensa de demostrarlo le surte la obligación de hacerlo, sino de la carga de acreditar los hechos que se pretenden incorporar al juicio para ser valorados. Los cuales bajo el principio de contradicción, intentan socavar la hipótesis del delegado del ente acusador, que al fin de cuentas serán valorados teniendo en cuenta la sana crítica y la presunción de inocencia.

En providencia AP4159-2017 la Corte inadmitió una demanda de casación donde se enjuicia una providencia de segunda instancia por cuanto según el censor se dinamizó la carga de prueba al condenar a los acusados del delito de lavados de activos por asumir una defensa pasiva y faltar a la justificación del origen de los recursos económicos a su poder. Pues bien, el Tribunal de Casación advirtió que el ad quem dedujo a partir de un análisis conjunto de la prueba el acaecimiento de los hechos delictivos endilgados por cuanto en las investigaciones se demostró no sólo la existencia de cuentas con altísimas sumas de dinero cuyos titulares eran los implicados sino también la existencia de una lista con sus nombres, números de cuentas y las tarjetas débito en el inmueble donde residían dos personas condenadas por el delito de tráfico de estupefacientes. De esta manera, esa Corporación evidenció que en la sentencia recurrida no se configuró un castigo a la estrategia defensiva, al contrario, se tenían elementos de convicción para establecer la responsabilidad penal. Aclarándose que a pesar de la referencia a la dinamización probatoria que hizo el Tribunal local, se corroboró que efectivamente no fue el fundamento de la decisión por cuanto se contaron con suficientes evidencias para acreditar la condena. 
En sentencia de 2016, el Tribunal de Casación, examinó el proveído que condenó a un joven por el delito de homicidio en contra de su novia quien se encontraba en estado de gravidez. Donde se expuso que el fallador sentenció con base en hechos indicadores que analizados en conjunto dieron cuenta de la responsabilidad penal del acusado. Asimismo se dijo que la defensa en ejercicio de sus derechos puede estructurar hipótesis alternativas a la de la acusación a partir de datos incorporados por cualquiera de las partes que resulten probados dentro del proceso, empero, que sean verdaderamente plausibles y que por lo tanto puedan generar dudas razonables, elucubración que la misma Corte lo ha denominado "versión plausible de inocencia" queriendo significar con ello que la defensa puede plantear enunciados fácticos diferentes a la teoría del caso del ente investigador, los cuales deben resultar acreditados su factible ocurrencia, de lo contrario, no tendrían vocación de prosperidad suficiente para generar duda razonable una vez se acrediten todos los elementos del tipo penal.

Esto tampoco resulta coherente con dinamización de la carga probatoria por cuanto, si la defensa pretender incorporar otras situaciones fácticas como una coartada, debe por lo menos soportarla con datos que resulten demostrativos de la posibilidad de su ocurrencia. Se otea también entonces que el estándar probatorio de los supuestos de hecho que pretender tener como probados la defensa, corresponde a una posibilidad de acaecimiento, que no a una ocurrencia más allá de toda duda razonable.

En reciente jurisprudencia (Corte Suprema de Justicia, 2018) se explicó que la procedencia de la carga dinámica de la prueba, depende de que la Fiscalía General de la Nación, en atención a la presunción de inocencia, cumpla con la acreditación sobre la existencia del delito y la participación del implicado y si la defensa pretende controvertir la capacidad suasoria de los elementos, debe aportar medios de convicción tendientes a refutarlos. Agregó que dicho concepto debe ser aplicado restrictivamente, no para que la defensa acredite lo que es deber del ente acusador, sino para desvirtuar lo probado por este, en atención a la necesidad de introducir criterios racionales en relación con la pretensión de las partes y las herramientas necesarias para demostrarlas. De lo anterior, se tiene que la Corporación determina la procedencia de la dinamización de la regla, empero, con un análisis teórico, se observa que no comporta propiamente un intercambio en la actividad probatoria, pues en ningún momento se prescinde del comportamiento demostrativo del ente fiscal, sino que se advera que en el evento en que la defensa sustente hipótesis contrarias, las deberá probar, lo que deviene en la más básica teoría de la carga de la prueba, que explica que quien tiene una pretensión la debe acreditar.

En sentencia de 2017, la misma Corporación afirmó que existe duda razonable cuando durante el debate probatorio se verifica la existencia de una hipótesis plausible contraria a la responsabilidad penal del procesado o que incida de alguna forma relevante sobre la misma. Suposición que puede ser introducida al juicio por la defensa, pero que en todo caso puede estar en la misma acusación o que el juez la advierta durante el juicio oral, así las partes no hagan alusión a ella expresamente. Como se observa, redunda en ventajas una defensa activa, por cuanto pone de presente en la mente del fallador mayores enunciados fácticos, que de contera podrían resultar en dudas razonables. Lo cual no implica una inversión de la carga probatoria, ya que de cualquier manera el juez está en la obligación de valorar todas las pruebas bajo la presunción de inocencia, el in dubio pro reo y con el barómetro de "más allá de toda duda razonable" de la pretensión de responsabilidad penal. 
En la misma providencia (Corte Suprema de Justicia, SP 19617-2017 Radicación $45899,2017)$ se indicó que al lado de los supuestos fácticos encaminados a probar todos los elementos estructurales del tipo penal, tanto los hechos jurídicamente relevantes como eventualmente los indiciarios, hacen parte del tema de prueba como también las circunstancias fácticas alternativas que proponga la defensa, lo que tampoco implica per se una dinamización de la carga de la prueba, sino que es la regla clásica consistente en que se deben probar las propias afirmaciones. Además, se explicó que en virtud de la presunción de inocencia la carga de la prueba radica en el ente acusador. En consecuencia, en el evento en que uno de los enunciados propuestos por la defensa no encuentre congruencia con las pruebas presentadas para su acreditación, no implica automáticamente la posibilidad de tener como cierta la tesis contraria, esto es, la acusación. Siendo que sólo podría tenerse de tal manera siempre y cuando se haya ofrecido suficientes elementos de juicio que la soporten con el estándar indicado, so pena de admitirse una condenada basada en la falacia ad ignoratiam ${ }^{4}$.

\subsection{Síntesis doctrinal sobre la dinamización de la carga de la prueba en el proceso penal}

Autores colombianos ${ }^{5}$ han criticado la regla jurisprudencia de carga dinámica de la prueba en materia penal por cuanto consideran que es violatoria de derechos y principios fundamentales que rigen el sistema procesal punible. Se ha dicho que esta fórmula es contraria i) al debido proceso en su contenido de que a nadie se le puede juzgar sino conforme con la plenitud de las formas de cada juicio, esto es, asumirse inocente hasta que no sea declarado responsable judicialmente, por lo tanto el acusado no está obligado a demostrar su inocencia; ii) a la presunción de inocencia ya que no es posible exigirle probar al procesado tal condición, ya que la misma se presume, en virtud del axioma constitucional; y iii) a la no autoincriminación, por cuanto, se le impone la carga de probar los elementos del tipo penal que la postre podrían determinar su culpabilidad (Páez Jaimes, 2018).

Y es que como la asunción de acreditación en la defensa de un deber que es del ente fiscal, la variación en comento indicaría que el órgano público prescinde de la carga sustancial de solicitar la práctica de pruebas y la recolección de evidencias para demostrar su pretensión condenatoria, puesto que, en algunas hipótesis delictuales resulta más accesible el medio de convicción para la defensa, lo que deviene en la supresión de axiomas del garantismo como nulla acusatio sine probatione y nulla probatione sine defensione (Betancourt Restrepo, 2010)

\section{Análisis teórico procesal de las posturas sobre la regla juris- prudencial de la carga dinámica de la prueba}

En términos generales, se tiene que el ordenamiento jurídico impone la carga de probar un hecho a una parte porque está en una mejor posición, porque tiene un interés jurídico o porque una norma se lo exige, entonces es ese extremo quien sufrirá las consecuencias desfavorables si lo omite (López Pinilla, 2016). Ahora, específicamente para el proceso penal el artículo 7 de la Ley 906 de 2004 establece como regla probatoria que le compete a la Fiscalía General de la Nación acreditar la responsabilidad penal del acusado, en concordancia con el artículo 381 del mismo estatuto que prescribe que para condenar se debe tener el conocimiento más allá de toda duda razonable sobre la ocurrencia del hecho punible y la responsabilidad

4. Consistente en proponer la verdad de una afirmación por el sólo hecho de que no se ha demostrado su falsedad. (Corte Suprema de Justicia, 2017) 5. Ver entre otros, Caro Espitia y Müller Rueda. 
penal del acusado, fundado en las pruebas debatidas en juicio. Así mismo el artículo 250 constitucional impone como obligación de dicha institución estatal adelantar el ejercicio de la acción penal.

De estas normas fácilmente se extrae que es un deber procesal del ente persecutor incorporar los elementos de convicción para demostrar -bajo el estándar de prueba referido- la materialización de una conducta reprochada en términos penales y su consecuente atribución al acusado. Y que también es una función del delegado del establecimiento acusador, la cual no se puede relevar haciendo uso del dinamismo de la carga de la prueba, que si bien se ha intentado introducir al proceso penal, se ha formulado y entendido de manera equívoca por las razones que se pasarán a explicar.

Como ya se dijo, el representante de la Fiscalía tiene la función de demostrar su teoría del caso, so pena de proferirse sentencia absolutoria por cuanto el juez no puede condenar si no encuentra acreditada la hipótesis acusatoria, así como tampoco puede este trasladar el tema de prueba, esto es, los elementos constitutivos del tipo penal (conducta, típica, antijurídica y culpable) a la defensa, con el argumento del principio de solidaridad apoyando al ente persecutor con su enunciado fáctico. Dígase de una vez que ello resultaría un contrasentido vulnerador de los principios que rigen el sistema procesal penal y que de ninguna manera se extrae dicha tesis de la jurisprudencia de la Corte Suprema de Justicia sobre el tema. Lo anterior por cuanto, en pronunciamiento alguno analizado se observó que la condena se cimentara en una falta de actividad probatoria de ambas partes y como consecuencia se utilizara un sucedáneo de prueba castigándose a la defensa con una providencia desfavorable por tener más fácil acceso a un medio de convicción que se echara de menos en la práctica probatoria, sino que, fueron decisiones fundadas en los elementos de juicio que soportaron suficientemente las respectivas pretensiones de culpabilidad, las cuales la defensa activa en términos probatorios, no logró desvirtuar, de donde se sigue que nunca se dinamizó la regla del asunto.

Y es que, como se explicó arriba, la dinamización de la carga de prueba se aplica en los otros ordenamientos procesales como un sucedáneo de prueba, que trae consecuencias procesales desfavorables a la parte que siéndole posible acreditar un hecho, prefiera desplegar comportamiento pasivo u omisivo. Empero, en tratándose del sistema penal, se insiste, resulta claro que el sucedáneo de prueba es el principio de inocencia o el in dubio pro reo, esto es, ante una falencia en la práctica probatoria, bien sea por ausencia de demostración o duda en lo que acreditó el ente fiscal, no se castiga a una de las partes por su actividad negligente, sino que, se favorece al procesado con sentencia absolutoria motivada en dichas garantías constitucionales. En pocas palabras, la lógica del sistema procesal penal ni ontológica ni deontológicamente pretende acudir a distribuir la acreditación de una determinada circunstancia fáctica para resolver su acaecimiento en contra de la parte que debía probarla.

En este orden de ideas, de la dinamización de la carga de la prueba en materia penal propuesta por la Corte Suprema de Justicia no puede inferirse la posibilidad de que un juez penal condene a un procesado porque no probó o dejó de demostrar las explicaciones para inferir su inocencia, eximiendo a la Fiscalía General de la Nación de la acreditación del tema de prueba. En contraste, como lo ha explicado reiteradamente el Alto Tribunal, una vez el ente persecutor demuestre cada uno de los elementos constitutivos del tipo punible endilgado y en el evento de que la defensa sea activa y pretenda introducir medios de convicción para demostrar su 
teoría del caso, lo deberá hacer con alguna suficiencia, incorporando hechos relevantes o indicadores que idóneamente controviertan el enunciado acusador. Porque de lo contrario, ante una hipótesis de responsabilidad suficientemente cimentada que logre mantenerse incólume en el debate probatorio con el parámetro de más allá de toda duda razonable, el funcionario judicial se vería compelido a condenar fundado precisamente en los elementos de conocimientos practicados en juicio, que no en la carencia de probanza de la inocencia.

El estándar probatorio surge como otro elemento que motiva el análisis que apoya la teoría de este escrito, esto es, la ausencia de dinamización de la carga de la prueba en materia penal. Recuérdese que el parámetro de más allá de toda duda razonable surge como exigencia para acreditar los enunciados fácticos del ente investigador. No obstante, este baremo no puede ser aplicado a la hipótesis de la defensa, por cuanto esta no debe acreditar los sustentos fácticos defensivos por encima del mismo, sino que lo pretendido con la aportación es generar una duda razonable que desvirtué la acusación. Coligiéndose que en el evento en que la defensa pretenda introducir elementos de conocimiento al juicio, lo podría hacer bajo un estándar de probabilidad de ocurrencia, que no más allá de toda duda razonable.

De esta manera, si bien el Tribunal de Casación ha insistido en dicha dinamización en iterados pronunciamientos esos postulados se deberían interpretar como una invitación a mantener una defensa activa requiriéndose de manera lógica un sustento de acreditación de su enunciado fáctico que procura ser objeto del juicio de hecho. Y no como un verdadero intercambio demostrativo de las circunstancias fácticas alegadas, con el específico estándar de prueba que se le exige a la Fiscalía General de la Nación, pero nunca al procesado.

Así las cosas, la presunción de inocencia es la hipótesis inicial que debe tener el juez, siendo que el enunciado fáctico de culpabilidad tiene como fin ponerla en tela de juicio, pero si no logra su cometido o en caso de duda de conformidad con el in dubio pro reo se debe declarar la inocencia como probada. En una palabra, la duda para que sea necesaria la aplicación de un sucedáneo de prueba no se presenta. En cambio, cuando comporta acreditada la teoría del ente acusador, siendo incompatible con la inocencia, se tendrá que condenar, por cuanto existen elementos probados para lo propio. (Nieva Fenoll, 2013). Con todo, en la valoración probatoria puede fulgurar la culpabilidad, sin embargo, ante el surgimiento de mayores hipótesis alternativas con algún grado de probanza se podría presentar la existencia de una duda, que tendría que ser resuelta a favor del acusado.

Por lo anterior, si se presentan versiones a favor de la inocencia, en atención a la corección de la decisión judicial como búsqueda de alternativas a la culpabilidad y con el fin de atender las soluciones a un problema fáctico penal, resulta conveniente que la defensa ejecute alguna actividad probatoria tendiente a, por lo menos, crear en el pensamiento del juzgador una alternativa a la teoría del caso del ente persecutor. La cual debe resultar acreditada sumariamente, no con el estándar de prueba más allá de toda duda razonable, es decir, que sea lógicamente plausible y coherente con los elementos de conocimiento que hayan sido incorporados por el investigado.

Y es que existen por lo menos tres heurísticos en la mente del juzgador al momento de decidir un asunto, que pueden generar sesgos epistemológicos, a saber: i) representatividad, que da cuenta de que se toma la decisión de acuerdo con lo que percibe como más exitoso, esto es, que a un mayor número de personas le ha funcionado; ii) 
accesibilidad, que se presenta cuando se resuelve de acuerdo con la situación análoga que mejor se recuerde, que necesariamente no tiene que coincidir con la más recurrente, sino con la que generó mayor impacto; y iii) anclaje y ajuste, que funciona cuando el sujeto cognoscente ha tomado una decisión y con el fin de materializarla y mantenerla, ancla y ajusta todos los datos de la realidad para seguir defendiendo la decisión como correcta, también conocido como sesgo de confirmación (Nieva Fenoll, 2013).

Una de las soluciones para la corrección de los anteriores mantos resulta ser la búsqueda de alternativas, formulando otros modelos mentales para intentar la solución del caso enjuiciado, siendo que cuando devenga una incapacidad en la localización de modelos diferentes en los que encajen los indicios del asunto analizado, podría decirse que la decisión es correcta. (Nieva Fenoll, 2013). Y si bien el juez tiene la hipótesis de presunción de inocencia en todo momento, dentro del proceso puede perderse la neutralidad hacia el enunciado fáctico que le resulte más convincente, bajo los criterios de duda razonable y probabilidad inductiva (Nieva Fenoll, La razón de ser de la presunción de inocencia, 2016). Es allí entonces donde una actividad probatoria activa por parte de la defensa resulta conveniente a los intereses del procesado, situación que se itera no comporta una inversión en la carga de la prueba.

Es que se debe partir de que la verdad en un proceso es parcial o por lo menos difícil de alcanzar por cuanto está supeditada a inferencias deductivas o inductivas que realice el fallador teniendo como fundamento las premisas fácticas que acrediten las partes conforme con su capacidad de reconstrucción histórica. Sin embargo, esas hipótesis se ven limitadas bajo el objeto del litigio mediante criterios de pertinencia, utilidad y conducencia. Sumado a que el centro del juicio de hecho no son únicamente circunstancias fácticas, entendidas como expresiones constatables en el mundo exterior, sino que también se deben apreciar situaciones subjetivas y probabilísticas (López Pinilla, 2016), verbigracia, el dolo o la culpa, que no son susceptibles de demostración con una evidencia física, sino que son conceptos que se construyen a partir de inferencias. Así, es común encontrar que elementos estructurales del enunciado acusador sólo puedan ser acreditados mediante inferencias, teniéndose que la relación del medio de prueba con el hecho jurídicamente relevante es indirecta toda vez que lo que la soporta es el hecho indicador venero de la inferencia que mantiene correlación con el supuesto normativo (Corte Suprema de Justicia, 2017).

Entonces, ¿qué hacer cuando la Fiscalía acredita a un alto nivel de probabilidad su hipótesis acusatoria y la defensa sea ausente en el despliegue demostrativo para por lo menos crear en el juez una duda razonable? Sin duda, se debe dar por plausible fuertemente el enunciado fáctico de culpabilidad, siempre y cuando cumpla con el estándar exigido. Empero, la sentencia condenatoria no podría fundamentarse en la falta de probanza de los enunciados de la defensa, porque ello sí sería una inversión de carga de la prueba, sino que debe tener su cimiento en los elementos traídos a juicio por parte del delegado del ente estatal, valorados en conjunto bajo la sana crítica, sin advertirse duda razonable. Al igual que la decisión de absolver, siguiendo a Nieva Fenoll, tampoco debe fundarse en la falta de prueba de la culpabilidad, sino en el mantenimiento incólume de la inocencia del imputado.

También debe fundamentarse en una valoración integral de las pruebas incorporadas, que dan cuenta de lo sucedido, sin aplicar la regla de juicio de la carga de la prueba en contra de la defensa por la inactividad probatoria, sino que al final del 
juicio de hecho se tiene un resultado, dos pretensiones en pugna y se debe decidir conforme las inferencias cuál resulta acreditada con el estándar respectivo. Se inicia con la presunción de inocencia que es derruida finalmente por la pretensión de la Fiscalía General de la Nación. Por ello, comporta indebido estigmatizar de conculcadoras de derechos a las defensas activas que propugnan por incorporar nociones de conocimiento de los hechos con el fin de que el juez tenga un panorama más amplio y menos límites epistemológicos para entender el problema litigioso.

Por último valga aclarar que algunos autores como López Pinilla (2016) consideran que la carga de la prueba, la presunción de inocencia y el estándar más allá de toda duda razonable resultan desdibujados cuando la defensa alega un eximente de responsabilidad, ejecutando una defensa afirmativa, donde la carga de la prueba se traslada a la defensa, quien debe acreditar su hipótesis asumiendo el estándar probatorio determinado, no obstante la carga de la prueba en tratándose de los eximentes de responsabilidad son ajenos al objeto de estudio por lo tanto en este escrito no se analiza esta situación. Con todo bastaría indicar que al fin de cuentas estas causales no constituirían la teoría del caso de la acusación, entonces no hacen parte del tema de prueba que corresponde a la Fiscalía General de la Nación porque de hecho, si con un examen de sus pruebas encuentra alguno acreditado tendría que pedirse y decretarse una absolución o preclusión -dependiendo de la etapa procesalen lugar de la condena.

\section{Conclusiones}

Partiendo de la idea de que el error judicial es inherente al proceso, de la incapacidad del mismo de producir certezas y bajo el deber del juez de pronunciarse de fondo, dice Nieva Fenoll que la carga de la prueba resulta necesaria en el evento de la ausencia de la prueba, por lo tanto, es la última ratio del sistema probatorio (2016), es decir, el juzgador debe preferir siempre los elementos cognitivos que sean incorporados. De ahí que entre mayores medios de conocimiento obren en el plenario mayor podrá ser su análisis y por lo tanto deviene una convicción posiblemente más cercana a la realidad. Empero, en algunas ocasiones pude presentarse una imposibilidad -material o por estrategia litigiosa- de la aportación de dispositivos probatorios, donde el fallador tendrá que utilizar un sucedáneo de la prueba conocido como la carga procesal para resolver la contienda, puesto que, parafraseando al autor en cita, pareciera que se prefiere incluso una solución mala a la ausencia de la misma (2013). Pero al fin de cuentas tal solución cuenta con suficiente motivación pues precisamente uno de los deberes del Estado de Derecho es solucionar los problemas de los ciudadanos por las vías legales en búsqueda de la paz social.

Es por ello que la carga de la prueba es un elemento capital para solventar un conflicto de la comunidad cuando se predique ausencia de elementos de convicción. Tiene como función principal servir como una regla de juicio consistente en que el juez ante la insuficiencia demostrativa de las evidencias aportadas debe resolver contra la parte que tenía la responsabilidad de acreditarla. También deviene como una regla de comportamiento de las partes enfrentadas que les indica la forma en que deben actuar en materia probatoria.

Respecto al proceso penal y a tono con la normativa nacional, palmario es que el deber de demostrar la teoría del caso acusatoria la ostenta la Fiscalía General de la Nación. Siendo que en el litigio se enfrentan sustancialmente dos pretensiones, culpabilidad y no culpabilidad, y la intención de sentencia favorable a la parte depende de su actividad con el fin de evitar una desventaja procesal, lo que deviene 
en una carga procesal, así, en principio, a cada quien le corresponde probar lo que alega. (López Pinilla, 2016), esto es, cada extremo litigioso debe acreditar sus dichos. No obstante, en todos los eventos de cara a la presunción de inocencia y al in dubio pro reo, cuando no se alcance el estándar más allá de toda duda razonable de la pretensión condenatoria porque el delegado del ente persecutor no desplegó con suficiencia su carga, se debe absolver. Dicho de otra manera, la ausencia de convicción de cara al estándar referenciado no podrá ser utilizada en contra de la defensa pues se encuentra protegida no sólo por los axiomas aludidos sino por la expresa prohibición de variación del deber probatorio.

Es que a pesar de que los litigantes -fiscal y defensa- deben demostrar sus pretensiones, se les aplican parámetros distintos, el primero frente a "más allá de toda duda razonable" mientras el segundo con generar una duda razonable le es idóneo para desvirtuar la petición de condena. Con todo, se insiste que la actividad probatoria de la defensa no genera una dinamización de la carga probatoria puesto que de manera alguna tendrá que probar factores que pertenecen a la acusación y menos tendrá que esforzarse en propender tener como ciertas sus afirmaciones cuando el despliegue técnico del delegado de la institución acusatoria fracase, pues sólo una consecuencia se genera ante esto y es la absolución, sin miramientos del comportamiento de la defensa. Colofón, cuando no se acreditan los elementos esenciales del tipo penal, no se presenta una dinamización de la misma en asuntos penales, por cuanto finalmente se deberá absolver.

Con todo, la Sala Penal de la Corte Suprema de Justicia en su jurisprudencia ha desarrollado el concepto de la carga dinámica de la prueba como una institución excepcional en el proceso, imponiéndole un deber a la defensa de aportar elementos de juicio cuando tenga acceso a ellos siempre y cuando estén en línea con sus intereses, sin determinar la consecuencia de la falta de incorporación, que si fuese en esencia una dinamización sería la condena, pero así no lo ha establecido, se insiste. Aunado ha establecido que para su procedencia la Fiscalía General de la Nación debe acreditar con el estándar del prueba correspondiente las hipótesis fácticas en que funda su pretensión condenatoria, esto es, siempre el ente persecutor debe desplegar su actividad sin justificación del comportamiento demostrativo del acusado puesto que si no alcanza con suficiencia el parámetro de verdad necesaria para condenar, se le absolverá, al margen de sus tratativas probatorias pues este último está amparado, sin excepción, en el principio de inocencia y en caso de duda se aplicaría el in dubio pro reo.

Así las cosas, a pesar de que la Corte ha explanado en sus providencias la presunta dinamización de la figura en estudio, lo cierto es que sobre los efectos jurídico procesales no ha advertido que se condene al procesado por su insuficiencia en la acreditación de sus hipótesis fácticas defensivas, por lo tanto, si bien es un llamado a que ambas partes incorporen evidencias para lograr un mejor análisis cimentado en mayores elementos, no se deriva técnicamente en un intercambio en las cargas demostrativas de las partes. Porque al fin de cuentas en las sentencias arriba citadas, siempre se valoró la prueba en conjunto y se llegó a la convicción necesaria bajo los parámetros procesales penales, sin tener en cuenta una distribución de roles probatorios y menos eximiendo al ente persecutor de sus deberes. Valga resaltar que el concepto así utilizado jurisprudencialmente manda un mensaje equivocado, como si se permitiera imponer una condena al enjuiciado por su falta de actividad probatoria cuando un hecho no se encuentre claro, relevando la responsabilidad de acreditar su pretensión que tiene la Fiscalía General de Nación. Afortunadamente, 
como se oteó en los últimos pronunciamientos, ha venido aclarando la postura e imponiéndose límites a la imprecisamente llamada "dinamización de la carga de la prueba en materia penal".

En resumen, la carga de la prueba en materia penal no resulta dinamizada porque como regla de juicio no funciona, el juez verifica el estándar probatorio con que se acreditaron los hechos endilgados al procesado sin examinar a quien le quedaba más fácil probarlos para imponerle una consecuencia negativa o dar por probado algún hecho en favor de la parte que tenía acceso a la prueba. Como regla de autorresponsabilidad de las partes, en principio si funcionaría, de cara a que se le impone el deber a las mismas de acreditar las circunstancias fácticas que pretenden hacer valer en juicio, empero, de ninguna forma se estaría ante la exigencia del mismo estándar probatorio, toda vez que la Fiscalía debe probar más allá de toda duda razonable cada enunciado, mientras que la defensa deberá sólo generar alguna duda razonable frente al acaecimiento de sus premisas. Y es que la carga de acreditar la responsabilidad penal en todos los casos será de ente persecutor, pero el acusado siempre podrá desplegar una actividad probatoria que propenda por desvirtuar los elementos del tipo, incorporando medios de convicción que deberán ser plausibles y coherentes, sin embargo, las gestiones demostrativas de la defensa se mantienen al margen de su resulta eficaz porque de cualquier manera en caso de duda se resolverá a favor del procesado, es decir, el delegado fiscal no puede obviar su carga en alguna deficiencia de su contraparte.

\section{Bibliografía}

Ávila Roncancio, D. A., Baquero Guerrero, M. A., Barrera Camero, J. A., Bohórquez , J. L., Montes Telléz, D. E., Muñoz Gómez, C., Valenzuela Rodríguez, T. A. (Diciembre de 2013). Hacia la racionalización de la carga dinámica de la prueba a través de las reglas de la experiencia. Revista Nueva Época, 19(41), 189-215.

Barbosa Castillo, G. (2015). La estretegia en el proceso penal. En Instituto Colombiano de Derecho Procesal, XXXVI Congreso colombiano de derecho procesal (págs. 49-56). Bogotá: Universidad Libre.

Caro Espitia, N. (2013) La carga de la prueba frente al principio de presunción de inocencia en el estado colombiano. En Verba luris (págs. 31-42) Bogotá: Universidad Libre.

Charry Rivas, D. (2015). La carga dinámica de la prueba. En Instituto Colombiano de Derecho Procesal, XXXVI Congreso colombiano de derecho procesal (págs. 10931115). Bogotá: Universidad Libre.

López Pinilla, A. (enero-junio de 2016). Estándar de la prueba y defensas afirmativas en el proceso penal. Análisis con referencia al caso colombiano y español. Revista Nuevo Foro Penal, 12(86), 151-192.

Mosquera Mosquera, F. (2015). La teoría de la carga dinámica de la prueba y el principio de presunción de inocencia (artículo $7^{\circ}$ de la ley 906 de 2004) según la interpretación realizada por la Sala de Casación Penal de la Corte Suprema de Justicia y la Corte Constitucional. Medellín: Universidad de Medellín. 
Müller Rueda, K. (2014) La carga de la prueba en el proceso penal acusatorio en Colombia: disyuntiva de aplicación en la jurisprudencia de las altas Cortes. En: Revista de Derecho Público No 32.

Nieva Fenoll, J. (2013). La duda en el proceso penal. Madrid : Marcial Pons Ediciones Jurídicos y Sociales S.A.

Nieva Fenoll, J. (2016). La razón de ser de la presunción de inocencia. Revista para el análisis del derecho, 1-23. Obtenido de http://www.indret.com/pdf/1203_es.pdf

Parra Quijano, J. (2011). Manual de derecho probatorio (18 ed.). Bogotá: Librerìa Ediciones del Profesional Ltda.

Taruffo, M. (Marzo de 2005). Conocimiento científico y estándares de la prueba. Jueces para la Democracia. Información y Debate(52), 63-73.

Corte Constitucional. (18 de julio de 1996). Sentencia C-319 de 1996. MP: Vladimiro Naranjo Mesa. Bogotá.

Corte Constitucional. (22 de noviembre de 2005). Sentencia C 1194 de 2005. MP: Marco Gerardo Monroy Cabra. Bogotá.

Corte Constitucional. (26 de junio de 2009). Sentencia C 417 de 2009. MP: Juan Carlos Henao Pérez. Bogotá.

Corte Suprema de Justicia. (25 de mayo de 2011). Radicación 35370 Sala de Casación Penal, MP Fernando Alberto Castro Caballero. Bogotá.

Corte Suprema de Justicia. (12 de octubre de 2016). SP 1467-2016 Radicación 37175. Sala de Casación Penal, MP Patricia Salazar Cuéllar. Bogotá.

Corte Suprema de Justicia. (22 de febrero de 2017). AP 1033-2017 Radicación 49622. Sala de Casación Penal, MP Fernando Alberto Castro Caballero. Bogotá.

Corte Suprema de Justicia. (28 de junio de 2017). AP 4159-2017 Radicación 49994. Sala de Casación Penal, MP Eyder Patiño Cabrera. Bogotá.

Corte Suprema de Justicia. (5 de abril de 2017). AP2313-2017 Radicación 49280. Sala de Casación Penal, MP Eyder Patiño Cabrera. Bogotá.

Corte Suprema de Justicia. (26 de abril de 2017). AP2649-2017 Radicado 46965. Sala de Casación Penal, MP Eyder Patiño Cabrera. Bogotá.

Corte Suprema de Justicia. (23 de agosto de 2017). Sentencia SP12849-2017 Radicado 48745. MP: Eugenio Fernandez Carlier. Bogotá.

Corte Suprema de Justicia. (23 de noviembre de 2017). SP 19617-2017 Radicación 45899. Sala de Casación Penal, MP Patricia Salazar Cuellar. Bogotá.

Corte Suprema de Justicia. (8 de marzo de 2017). SP 3168-2017 Radicación 44599. Sala de Casación Penal, MP Patricia Salazar Cuéllar. 
Corte Suprema de Justicia. (30 de mayo de 2018). AP 2162-2018 Radicación 52287. Sala de Casación Penal, MP Eugenio Fernández Carlier. Bogotá.

Corte Suprema de Justicia (20 de noviembre de 2018) AP4986-2018 Radicación 53597. Sala de Casación Penal, MP Eugenio Fernández Carlier. Bogotá.

Corte Suprema de Justicia (2 de septiembre de 2020) AP2157-2020 Radicación 57906. Sala de Casación Penal, MP Hugo Quintero Bernate. Bogotá. 